\title{
LOS POEMARIOS LÍRICOS EN EL SIGLO DE ORO: DISPOSICIÓN Y SENTIDO
}

\section{J. Valentín Núñez Rivera}

\begin{abstract}
This article attempts to portray the most frequent trends in the textual dispositio of the lyric books of poems (books of authors or anthologies), which were written during the Golden Age. These trend may be generally summarized by the use of a generic and strophic criteria, or by a semantic and referential organization: in both cases the variety is abundant, which is due to certain editorial or authorial factors and criteria, the most important of which, is due to specific rethorical determining factors. Furthemore, the most influential structural patterns and their effects in the current spanish book of poems, are studied and analyzed: the canon of Petrarch' Canzoniere and the works of Boscán and Garcilaso in 1543.
\end{abstract}

A la altura de 1543, con la publicación de Las obras de Boscán y algunas de Garcilaso (Barcelona, Carles Amorós, 1543) quedaba inaugura la polaridad octosílabos frente a endecasílabos en el panorama de las letras españolas. Según consta en el título del tomo, las composiciones van repartidas en quatro libros, los tres primeros dedicados a la obra del poeta barcelonés y el último a Garcilaso. Centrándonos por ahora en la obra de Boscán, el principio organizativo básico de separar los versos octosilábicos de los endecasilábicos se expone por dos veces en el libro. En el prólogo "A los lectores" -posiblemente redactado por la viuda del poeta, Ana Girón de Rebolledo, que se encargó de preparar la edición- se anuncia que van: “...En el primero las primeras cosas que compuso que son coplas españolas, y en el segundo, canciones y sonetos a manera de los ytalianos, y en el tercero, epístolas y capítulos y otras obras también a la ytaliana"1. El propio Boscán en la carta "A la duquesa de Soma", que abre el libro segundo, enuncia idéntico sistema: "En el primero avrá vuestra señoría visto essas coplas (quiero dezillo assî) hechas a la castellana. Solía holgarse con ellas un hombre muy avisado y a quien vuestra señoría deve de conocer muy bien, que es Don Diego de Mendoça. Mas paréceme que se holgava con ellas como con niños, y assí las llamava las redondillas. Este segundo libro terná otras cosas hechas al modo italiano, las cuales serán sonetos y canciones...".

\footnotetext{
${ }^{1}$ Cito por la edición de C. Clavería, Las obras de Boscán de nuevo puestas al día y repartidas en tres libros, Barcelona, PPU, 1993, p. 5.

${ }^{2}$ Ed. cit., p. 229.
} 


\section{Criterios genéricos}

Esta oposición "coplas catellanas / metros italianos", que tomó carta de naturaleza en la edición barcelonesa, se erigió como modelo organizativo canónico de muchas de las posteriores colecciones poéticas. Puede aplicarse a una estructura bipartita como en Núñez de Reinoso, Historia de los amores de Clareo y Florisea, y de los trabajos de Ysea: con otras obras en verso, parte al estilo Español y parte al Italiano (Venecia, Gabriel Giolito de Ferrari, 1552), el cual lo reitera en la portadilla a las composiciones poéticas: Libro segundo de las obras en coplas castellanas y versos al estilo italiano. Igualmente se observa en Las obras de Diego de Fuentes (Zaragoza, Agustín Millán, 1563), donde "se hallarán la mayor parte de las que él ha hecho, así canciones como sonetos y otros géneros de verso". El primer grupo contiene rimas a la española (canciones villancicos, coplas, glosas, romances, ff. 1-54); la "Segunda parte de las obras"..."trata de sonetos y octavas rimas, tercetos, canciones, sextinas, con otros géneros de verso" (ff. 55-112). Y del mismo modo lo asume López Maldonado en el Cancionero (Madrid, Guillermo Droy, 1586), con una sección primera que acoge redondillas, glosas y villancicos, y una segunda formada por octavas, canciones, sonetos y églogas. Lomas Cantoral, Obras (Madrid, Pierres Cosín, 1578) propone, por su parte, una estructura tripartita siguiendo a Boscán: el primero de los libros contiene las coplas castellanas y los otros dos los metros "a la italiana"3. Es posible además la cuatripartición, como en Las obras de Gregorio Silvestre (Lisboa, Manuel de Lyra, 1582), publicadas bajo el auspicio de Pedro de Cáceres y Espinosa. Él mismo explica en el prólogo al cuarto libro el sentido de tal modelo distributivo: "En el primero pusimos aquellas de que los poetas españoles antiguos usaron... En el segundo se pusieron las fábulas Audiencia y Residencia... de excelente gravedad y autoridad. En el tercero, las obras morales y de devoción... En el cuarto y último ponemos los sonetos y canciones y epístolas que hizo, y la fábula de Narciso" (ff. 296-296v). Estuvo de tal modo atento Cáceres al modelo de Boscán que en el "Discurso breve sobre la vida y costumbres de Gregorio Silvestre" que abre el libro, relata cómo los poemas en octosílabos son producto de una primera etapa creadora, mientras que la práctica italianizante se debe a un momento compositivo de madurez. De ahí la disposición consecutiva "octosílabos-endecasílabos" sustentada sobre un criterio múltiple, no sólo métrico o de escuelas poéticas, sino también de cronología creadora: "Debía de tener ya más de veintiocho años quando comenzó a tener nombre entre los que se preciaban de componer los versos españoles que llaman rimas antiguas, y los franceses redondillas. A las cuales se dio tanto, o fuese por el amor que tuvo a Garci-Sánchez y a Bartolomé de Torres Naharro y a D. Juan Fernández de Heredia, a los

\footnotetext{
${ }^{3}$ J. I. Díez Fernández, "Disposición y ordenación de las Obras de Jerónimo de Lomas Cantoral”, BBMP, LXIX (1993), pp. 53-85, ha tratado de las peculiaridades de la edición preparada y revisada por él mismo, quien explica su propia voluntad ordenadora en tres libros: el primero en coplas castellanas y los otros dos, en metro italianizante, una división tripartita que viene a coincidir con la dada por Boscán, tanto por establecer un primer libro con obras en metro castellano, como por ofrecer un tercero de "diferentes propósitos", dejando entre ellos un segundo de historia amorosa con su normativa alternancia de formas métricas. De todos modos, la estructura boscaniana es superada por un deseo de variedad, que Díez Fernández califica de estética manierista (p. 84). La dispositio tripartita de primer nivel se complementa con una cuidada colocación de los poemas en cada uno de esos grandes apartados. Según explica Díez Fernández: "Como un refuerzo de especial intensidad, Lomas Cantoral ha ordenado con cuidado los finales de los tres libros siguiendo una estructura paralelística en la disposición de los poemas y una intensidad creciente en los contenidos morales y religiosos... La moralidad de los sonetos-prólogo, más allá de la exigencia petrarquista, enmarca en Las obras una justificación, confirmada en los finales de los tres libros", p. 79.
} 
cuales celebraba aficionadamente que no pudo ocuparse en las composturas italianas que Boscán introdujo en España en aquella sazón. Y así, imitando a Cristóbal de Castillejo, dijo mal de ellas en su Audiencia. Pero después, con el discurso del tiempo, viendo ya que se celebravan tanto los Sonetos y Tercetos y Octavas... compuso algunas cosas dignas de loa..." ( $\sin$ fol.).

Sin embargo, las cosas van a ir cambiando sustancialmente conforme nos acercamos al XVII, de lo cual son buena muestra, por ejemplo, las Diversas Rimas (Madrid, Luis Sánchez, 1591) de Vicente Espinel, cuya edición fue cuidada por él mismo. Frente al modelo anterior, el volumen se inicia con las composiciones de arte mayor ${ }^{4}$ y sólo a partir del f. 114 se incluyen las coplas castellanas, si bien se intercalan algunos sonetos. Esta postura podría interpretarse como un síntoma del cuestionamiento frente a una pretendida evolución poética desde el octosílabo al endecasílabo, tal como se reflejaba en el modelo organizativo de raigambre boscaniana, que quizá sí estaba dotado de sentido en sus particulares circunstancias, pero que no resultaba en absoluto operativo para los poetas posteriores a 1580, usuarios de las dos prácticas poéticas de manera acompasada y paralela. Tan es así, que la dispositio canónica en las ediciones del siglo XVII relega los versos octosílabos al último lugar, iniciándose los volúmenes con la serie de los sonetos ${ }^{5}$ y continuándose con otras combinaciones endecasilábicas reagrupadas según el sistema genérico pertinente. Ejemplos de esta tendencia son las colecciones de Carrillo y Sotomayor, Obras, Madrid, Iuan de la Cuesta, 1611 (publicadas por Alonso Carrillo Lasso, hermano del autor) ${ }^{6}$; Luis de Camoens, Primera y segunda parte de las Rimas, Lisboa, Pedro Craesbeeck, 16167; Antonio de Paredes, Rimas, Córdoba, Salvador de Cea, 16228; Manuel de Faria e Sousa, Divinas y hvmanas flores, Madrid, Diego Flamenco, 1624; Gabriel Bocángel, Rimas y prosas ivnto con la Fabula de Leandro y Ero, Madrid, Iuan Gonçalez, 1627 ${ }^{10}$; La lira de las Mvsas, de Hvmanas, y Sagradas vozes, junto con las demas obras Poeticas antes divulgadas, Madrid, Carlos Sánchez [s.a.:1637] ${ }^{11}$; Góngora en el Manuscrito Chacón de $1628^{12}$;

\footnotetext{
${ }^{4}$ Sonetos, canciones, octavas, cartas, aunque en los ff. 78-80 se incluyen dos redondillas y una glosa.

${ }^{5}$ La colocación inicial de los sonetos, ocupando, por tanto, el lugar preponderante de apertura, se corresponde con su situación en la jerarquía métrica preceptiva como estrofa culta más prestigiada ("la más hermosa composición i de mayor artificio i gracia de quantas tiene la poesía Italiana i Española", a juicio de Herrera). Además de que su poética permitía desde Petrarca una poetización de la biografía espiritual del yo ficticio.

${ }^{6} 50$ sonetos (ff.1-25v.); Fábula de Acis y Galatea; églogas, canciones, lyras, estancias, elegía; romances, letras, redondillas, aunque las composiciones octosilábicas suelen ir más mezcladas a partir del f. 55. Sobre la "razonada" dispositio editorial de Carrillo, ha tratado B. López Bueno en un trabajo todavía inédito, "Teoría de los géneros vs. teoría de los estilos. A propósito de un prólogo de 1611".

${ }^{7}$ Sonetos / canciones, odas, elegías, octavas, églogas / redondillas.

${ }^{8}$ Sonetos / octavas, odas, estancias, tercetos / décimas, romances, letrilla; a partir del f. 45 las Rimas sacras: sonetos, octava, quintillas, glosa, letrilla.

${ }^{9}$ Sonetos (ff. 1-27); poesía endecasilábica, ff. 28-106v (según géneros: fábula, octavas, sextinas, tercetos, canciones, madrigales) f. 107, Diuinas y humanas flores. Segunda parte: romances, décimas, glosas, letras, redondillas, seguidillas, epitafios, epigramas.

${ }^{10} 26$ sonetos, ff. 32-50v (elegía, epístola, égloga amorosa). A partir del f.51 la poesía octosilábica.

${ }^{11}$ Sonetos, hasta f. 20v. Epístolas y elegías; décimas, epigramas, romances; a partir del f. 67v., Lira de vozes sagradas. Versos a divinos y varios intentos.

${ }^{12}$ Este primer tomo contiene: sonetos, octavas, tercetos, canciones, madrigales, silvas, décimas, quintillas, redondillas; sonetos: sacros, heroicos, morales, fúnebres, amorosos, satíricos, burlescos, varios; canciones y madrigales; obras en décimas, quintillas y redondillas. El Tomo segundo de las obras de D. Luis de Góngora contiene: letrillas, romances,
} 
Miguel Colodreros de Villalobos, Varias rimas, Córdoba, Salvador de Cea Tesa, 1629'; Villamediana en sus ediciones de Zaragoza, 1629 y Madrid, 1635 $5^{14}$; Francisco de Borja, príncipe de Esquilache, Las obras en verso, Madrid, Diego Díaz de la Carrera, $1648^{15}$; Salcedo Coronel, Rimas, Madrid, Juan Delgado, $1627^{16}$ y Cristales de Helicona, Segunda parte de las Rimas, Madrid, Diego Díaz de la Carrera, 165077; Trillo y Figueroa, Poesías varias heroicas, satíricas y amorosas, Granada, Imprenta Real, 1652 $2^{18}$; Ulloa y Pereira, Versos sacados de algunos de sus borradores (Madrid, Diego Díaz, 1659) ${ }^{19}$.

Una vez considerada la oposición global en metros tradicionales frente a italianizantes, que caracteriza a las primeras colecciones poéticas del Quinientos, resulta preciso analizar la ordenación específica que normalmente estructura la seccción de metros endecasílabicos. De modo muy general puede sostenerse que son dos las tendencias observables: la disposición en grupos genéricos compartimentados, o bien la alternancia de esas distintas formulaciones métricas. Al primer grupo pertenece el libro cuarto de la edición barcelonesa, dedicado a las obras de Garcilaso. Aparecían reunidas por grupos compactos en función del género poético (29 sonetos, 5 canciones, 2 elegías, 1 epístola y 3 églogas) que podrían agruparse en dos secciones más amplias correspondientes a los modelos petrarquistas (sonetos y canciones) frente a los ensayos neoclásicos (oda, epístola, elegías y églogas). Existían, a pesar de todo, algunas anomalías en la colocación, consecuencia quizás de las prisas con que se llevó a cabo la edición: el soneto "Passando el mar Leandro el animoso" se dispuso después del índice, con la advertencia de "Soneto de Garcilaso, que se oluidó de poner a la fin con sus obras", y la Canción I se colocó entre los sonetos XVI y XVII (reagrupada más tarde por Herrera en su lugar correspondiente). La diferencia con Boscán radica, por tanto, en que en el libro II de este último aparecen entremezclados sonetos y canciones y en el III el resto de poemas italianizantes. El Brocense en la edición salmantina de 1574, gracias a la utilización de un "libro de mano" muy antiguo que le fue comunicado, añade al corpus inicial seis nuevos sonetos (incrementado con tres más en la revisión de 1577) y cinco coplas en octosílabos. Estos versos tradicionales se emplazan en último lugar, cerrando el volumen. Sólo en las ediciones

obras añadidas. Cito por la edición facsimilar del ms. (Málaga, RAE, 1991, 3 vols.).

${ }^{13}$ Sonetos (pp. 1-48; aunque en la p. 40 aparecen octavas y en la p. 41, letrillas); pp. 49-105: silva, fábulas; romances (pp. 107-154); epigramas (pp. 155-165); Desde p. 167 acaba con 4 sonetos y dos romances.

- ${ }^{14}$ F. Ruiz Casanova en su edición de la Poesía impresa completa del conde de Villamediana (Madrid, Cátedra, 1990) indica haberse basado para las cuestiones dispositivas en diferentes ediciones consultadas, ordenando el corpus en: sonetos (amorosos, líricos, sacros, fúnebres, satíricos); octavas-tercetos-cartas-silvas-fábulas-octosílabos... M. T. Ruestes, por su parte, (Poesía, Barcelona, Planeta, 1992) se guía por la princeps: sonetos (sacros, líricos, amorosos, fúnebres, satíricos)...

15 "Versos humanos": sonetos (pp. 1-71); otros metros endecasilábicos (72-370); décimas, redondillas, coplas, glosas; p. 406, "obras sueltas" (octosílabos); a partir de p. 412, romances; después de p. 576, "versos divinos".

${ }^{16} 14$ sonetos, canción, sonetos XV-XX, elegía I, silva I y II, sonetos, madrigales I y II, elegía II.

1754 sonetos, canciones, silvas, epístolas, elegías, octavas, romances, romances sacros, letras sacras, décimas, epigramas, glosa.

${ }_{18} 50$ sonetos; Fábula de Leandro (romance); romances; letrillas satíricas. Vid. para la implicación genérica de tal secuenciación Pedro Ruiz Pérez, "El sistema de los géneros poéticos en Francisco de Trillo y Figueroa", Glosa, 2 (1991), pp. 289-306.

${ }^{19}$ Sonetos, ff. 1-45. Otros endecasílabos: 45v-103v. La Raquel (octavas), epístolas. Octosílabos, ff. 103v-158v. Siguen la Paráfrasis de los siete psalmos penitenciales y Soliloquios en romances castellanos. 
modernas ocuparán la posición inicial, siguiendo un modelo cronológico preestablecido de considerarlos como punto de partida de la trayectoria poética garcilasiana.

El libro segundo del barcelonés, sin embargo, incluye sonetos y canciones, que a modo de un canzoniere canónico, combina ambos tipos de composiciones. El libro III, por su parte, se reserva a los géneros de prosapia clasicista forjados en composiciones de mayor envergadura y empuje, una clara decisión de trascender el modelo petrarquesco (la Fábula de Hero y Leandro en verso suelto, varios ensayos epistolares y la octava rima). La misma distinción, por tanto, que opera en el libro de Garcilaso, donde, como hemos visto, existen dos macroestructuras fundamentales en torno a los géneros petrarquistas: por un lado sonetos y canciones; ensayos neoclásicos, por otro. Boscán hubo de considerar este cuarto libro como colofón del volumen y quizá debido a ello suprimió las composiciones en octosílabos con "la intención [según considera Antonio Armisén] de presentar la poesía del libro IV como estadio final que culmina la superación formal y expresiva que los tres libros anteriores desarrollan"20. La diferencia fundamental entre ambos libros, radica, no obstante, en que sonetos y canciones aparecen en Boscán mezclados, mientras que en Garcilaso forman compartimentos estancos. Precisamente ambas posibilidades fueron y son por esos mismos años comunes en las colecciones poéticas italianas. La alternancia estrófica es propia del modelo del Canzoniere petrarquesco fundado en el vario stile, que conocerá una larga estela de continuadores a lo largo del siglo XVI, como G. G. Trissino, Rime (Vicenza, Tolomeo Ianiculo, 1529); J. Sannazaro, Sonetti e canzoni (Napoli, Gio. Sultzbach, 1530); L. Ariosto, Le Rime (Venezia, I. Modanese, 1546); A. Firenzuola, Rime (Firenze, G. Giunti, 1549); G. Stampa, Rime (Venezia, 1554); A. Minturno, Rime e prose (Venezia, Francesco Rampazetto, 1559); B. Rota, Sonetti e canzoni con l'Egloghe piscatorie (Venezia, Giolito, 1560); G. della Casa, Rime e prose, Florencia, 1564. Ese modelo será prestigiado igualmente en España por una serie de colecciones poéticas (las de Acuña, Herrera, Cuevas Espinel), sobre las que trataré enseguida. En todos los casos la organicidad se basa en un orden interno de secuencialidad cronológica o histórica ${ }^{21}$. Sin embargo, el Canzoniere mismo constituirá el germen de la división posterior en secciones o paradigmas métricos a partir de ediciones petrarquescas del Quinientos, por ejemplo los Soneti, Canzoni e Triomphi di M. F. Petrarca con la spositione di Bernardino Daniello da Lucca (Venecia, Giovanni Antonio di Nicolini da Sabio, 1541). Incluso dos traduciones castellanas de la segunda mitad del XVI se adscriben al mismo sistema organizativo. Se trata de Los Sonetos, Canciones, Mandriales y sextinas del gran Poeta y Orador Francisco Petrarca traducidos del toscano por Salusque Lusitano (o Salomón Usque Hebreo, Venecia, Nicolao Bevilaquia, 1567)22 y Los Sonetos y Canciones del Poeta Francisco Petrarcha, que traduze Henríque Garcés de lengua Thoscana en castellana (Madrid, Guillermo Droy, 1591). Hacia 1550 -aunque hay ejemplos muy anteriores como la reordenación de F. Flavio de las Opere de S. Aquilano (Venecia, 1502)- los petrarquistas italianos tienden a confeccionar canzonieri alejados del modelo

\footnotetext{
${ }^{20}$ A. Armisén, Estudios sobre la lengua poética de Boscán. La edición de 1543, Zaragoza, Universidad-Pórtico, 1982, p. 424.

${ }^{21}$ Carlos Clavería intuye una sucesión cronológica en la organización de los poemas en el libro II de Boscán. Cfr. ed. cit., p. XXXVIII.

${ }^{22}$ Vid. M. P. Manero Sorolla, "La primera traducción de las Rime de Petrarca en lengua castellana: Los sonetos, canciones, mandriales y sextinas del gran poeta y orador Francisco Petrarca, de Salomón Usque" en Homenaje al profesor Antonio Vilanova, ed. de A. Sotelo y M. C. Carbonell, Barcelona, Universidad, 1989, vol. I, pp. 377-391.
} 
original. Para ello no superponen piezas de distinto esquema estrófico, sino que las emplazan en apartados separados por su unidad métrica, rechazando, por lo tanto, la organización fragmentaria. Ejemplos significativos son los de L. Tansillo, Le lagrime di san Pietro...giuntavi... la racolta dell sue rime (Venezia, Francesco Piacentini, 1737) ${ }^{23}$; L. Alamanni, Opere toscane (Lion, Sebastian Gryphius, 1532) ) $^{24}$ B. Tasso, Rime, (Venezia, Giolito, 1560) $)^{25}$.

El canon dispositivo popularizado por Petrarca en su Canzoniere se basa en un orden interno de secuencialidad cronológica, que, por lo demás, se instaura de modo general en paradigmas arquetípicos de la cosmovisión humana ${ }^{26}$. Cada uno de los rerum vulgarium fragmenta que componen el libro se dispone secuencialmente como hito significativo de un proceso vital mas amplio, centrado en los avatares de su propia historia amorosa. Tal iter vivencial, que no necesariamente autobiográfico, constituye por tanto el eje sobre el que se va a articular la hipotética reconstrucción de la secuencia de sonetos y canciones. La extensión in ordine de cada uno de los ictus del proceso narrativo habrá de hilvanarse, así pues, mediante la dispositio progresiva de series poemáticas o compositivas, englobadoras a su vez de aquellos poemas que presenten entre sí una evidente solidaridad semántica. La presencia de conexiones intertextuales entre los diferentes micro-textos proporcionará la pauta para adscribir cada composición a una determinada etapa del decurso macrotextual. Criterio estructurante que permitirá agrupar los poemas en virtud de una tópica recurrente (metaforía, apelaciones míticas) o de su semejanza retórica, etc. Dos de las marcas estructurales más evidentes son la presencia de un soneto-prólogo, límite inicial de la cornice temporal y contrapunto de la palinodia final ${ }^{27}$, y la bipartición in vita/in morte de Laura, que, no obstante, se sustituye en otros muchos casos (por ejemplo en Acuña, Espinel, o Soto de Rojas) por la dicotomía entre el amor pasado y el desengaño de la madurez (o la vejez) desde cuya atalaya se reconsidera como giovenile errore. Mediante el arrepentimiento o retractatio amorosa el poeta pretende reconducir sus pasos hacia la liberación total de los lazos sensuales, supliendo ese amor terrenal por una vía progresivamente ascendente hacia la divinidad. Tras el desengaño terrenal la única posibilidad que se abre ante el poeta es la esperanza de una vida devota. Para conseguirla debe renunciar sin ambages a los dictámenes de la sensualidad y emprender una mutatio animi más conforme a la edad senil. Ese sería el último peldaño en el progressus argumental con el que se cancela el Canzoniere (poemas 364-265) ${ }^{28}$. La palinodia devota suele coincidir con la madurez-vejez del poeta, perspectiva desde la que por ejemplo, Petrarca

\footnotetext{
${ }^{23}$ Sonetos, canciones, madrigales, terzine, canciones y églogas compartimentadas.

${ }^{24}$ Se separan elegías, églogas, sonetos, Fábula de Narciso, sátiras, salmos, selvas...

${ }^{25}$ División de la obra en libros. El I sólo de sonetos. II, sonetos y canciones van mezclados; luego, himnos y odas, selvas, epitalamio, fábula, égloga, elegías.

${ }^{26}$ En analogía con el progreso inevitable de la juventud a la vejez, la ilusión al desengaño, el enamoramiento al desamor..

${ }^{27}$ Para las características funcionales del soneto-prólogo véase el artículo de J. M. Rozas, "Petrarca y Ausias March en los sonetos-prólogo amorosos del Siglo de Oro", Homenajes. Estudios de Filología Española, I (1964), pp. 57-75 y más recientemente J. L. Romero, "Soneto-prólogo y cancionero petrarquista en la lírica de la Edad de Oro", Trivium, 6 (1994), pp. 427-435.

${ }^{28}$ Como ha estudiado K. Foster, Petrarca. Poeta y humanista, Barcelona, Crítica, 1989. Véase asimismo M. Casali, "Petrarca «penitenziale»: dal Salmi alle Rime", Lettere italiane, 20 (1968), pp. 366-82.
} 
enjuicia negativamente los avatares poético-amorosos de su juventud, creando un marco metapoético que se instala en esos nuevos presupuestos penitenciales (la cornice) $)^{29}$. El canon petrarquesco subyace más o menos implícito y con variaciones en una serie de colecciones poéticas españolas como las de Acuña ${ }^{30}$, Herrera $^{31}$, Cueva $^{32}$, Figueroa ${ }^{33}$ o Espinel ${ }^{34}$, a pesar de que debido a distintos avatares editoriales el resultado impreso haya deparado la presentación de conjuntos más o menos desorganizados. Antonio Prieto así lo argumenta en La poesía española del siglo XVI: "Evidentemente, en nuestra poesía del siglo XVI existen cancioneros que pueden denominarse petrarquistas por responder a su modelo..., pero esos cancioneros petrarquistas españoles, por el abandono editorial citado, se encuentran desorganizados,

${ }^{29}$ Esta valoración global de la vida y de la obra conoce ilustres precedentes en la poesía latina (Horacio, Propercio u Ovidio) como ha mostrado F. Rico, "Prólogos al Canzoniere (Rerum vulgarium fragmenta, I-III)", Annali della Scuola Normale Superiore di Pisa, III, XVIII, 3 (1988), pp. 1071-1104. Los ejemplos españoles resultan asimismo abundantes. Puedo apuntar los casos de Cristóbal de Mesa (Valle de lágrimas y diversas rimas, Madrid, Juan de la Cuesta, 1607). Comienzan las rimas con una dedicatoria, refiriéndose a las obras amorosas: "La edad de 45 años en que yo me hallo y el hábito eclesiástico que tengo, más son para tener arrepentimiento de haberlas [rimas amorosas] hecho y formar escrúpulo de publicarlas"; en la ed. de Figueroa de 1625 existe un Breve discurso de Luis Tribaldos de Toledo, sobre la vida de Francisco de Figueroa: "En estos dias ya no tratava de Poesia, sujeto a que en su juventud fue mas inclinado, sino de materias de differente punto segun la madurez de su edad: en cuya loçania escriviò cosas dignas de perpetua recordacion..." (C. Maurer, Obra y vida de Francisco de Figueroa, Madrid, Istmo, 1988, p. 423); Quevedo, Heráclito cristiano y Segunda arpa a imitación de David (1613). Al lector: "Tú que me has oído lo que he cantado y lo que me dictó el apetito, la pasión o la naturaleza, oye ahora, con oído más puro, lo que me hace decir el sentimiento verdadero y arrepentimiento de todo lo demás que he hecho: que esto lloro porque así me lo dicta el conocimiento y la consciencia, y esas otras cosas canté porque me lo persuadió así la edad". A doña Margarita de Espinosa, mi tía: "Esta confesión, que por ser tan tarde hago no sin vergüenza, envío a Vm. para que se divierta algunos ratos; bien que empleándolos todos en su viudez y retiramiento, con Dios, antes será hurtárseles. Sólo pretendo, ya que la voz de mis mocedades ha sido molesta a Vm. y escandalosa a todos, conocer por este papel diferentes propósitos..." (Quevedo, Poesía original completa, ed de J. M. Blecua, Barcelona, Planeta, 1990, p. 17). Algunas de estas palinodias y otras más ha analizado O. H. Green, "El pródigo y su vuelta", en España y la tradición occidental, Madrid, Gredos, 1969, I, pp. 306-345.

${ }^{30}$ Varias poesías (Madrid, P. Madrigal, 1591) fue publicado once años después de su muerte por su esposa doña Juana de Zúñiga. El proceso secuencial de este corpus poético como cancionero no se corresponde con el orden efectivo de la edición, de tremenda irregularidad: sin ningún criterio temático, formal o cronológico. Se incluyen poemas ajenos y se repite alguno, caos que ha de achacarse a la intervención de la viuda.

${ }^{31}$ Vid. I. Pepe Sarno, "Itinerario di un amore. «Algunas obras» di Fernando de Herrera come Canzoniere" en Dialogo. Studi in onore di Lore Terracini, ed. de I. Pepe Sarno, Roma, Bulzoni, 1990, II, pp. 479-493.

${ }^{32}$ Obras, Sevilla, Andea Pescioni, 1582. Ya en el Prólogo de Diego Girón “Al lector" se aprecia la importancia del canon petrarquesco del vario stile:"Mas despues que hallo mayor volumen del que pensaua en sus obras, a ruego de algunos amigos, que con el tienen autoridad, quiso sacar algunas a la luz por muestra de lo que para adelante se deve esperar de su ingenio, con quien justamente se puede onrar su partria... Van mescladas las composiciones, porque aqui no se pretendio alguna orden de division, sino solamente el vario gusto de los leyentes, los cuales pueden ir escogiendo mientras leen las que más hazen a su paladar, i dexar las otras para los que a su elecion tienen por mejores aquellas, que otros no estiman por buenas" (ff. 6-6v.).

${ }^{33}$ Obras de Francisco de Figueroa, Lavreado Pindaro hespañol. Publicadas por... Luis Tribaldos de Toledo, Lisboa, Pedro de Craesbeeck, 1625. Su editora moderna, M. López Suárez (Madrid, Cátedra, 1989) considera que: "Pese a rechazarse una estructura de Canzoniere, el corpus poético de Figueroa se puede organizar en una serie de núcleos temáticos interrelacionados y con una progresión interna que responde a la evolución de la historia amorosa... En una perspectiva general la historia tiene su inicio en un tiempo de correspondencia amorosa, que caminando hacia un desdén incrementado por ausencia, desembocará en la traición y en el posterior desengaño del sentimiento de amor. Tras este desengaño... el poeta manifiesta un deseo de la liberación del yugo amoroso y una preocupación por el alma, como parte imperecedera que liberada de la cárcel del cuerpo, se reconducirá al primer motor" (p. 68). Sin embargo, la princeps obedece a un criterio global de distribución métrica: sonetos, canciones y las denominadas elegías.

34 J. Lara Garrido, "Manierismo estructural y desarrollo manierista del signo en las «Diversas rimas» de Vicente Espinel", en Estudios sobre Vicente Espinel, Málaga, Universidad, 1979. 
perdidos entre obras varias o sencillamente interrumpidos, en su lectura secuencial, por cierta costumbre editora de agrupar las composiciones por formas métricas contra el sentido alternante de una vida proyectada en palabra poética"35. Esa es la razón por la cual se muestra partidario de una reestructuración en cancionero (dándole al término el carácter marcado de secuencialidad cronológica) de todos esos corpus "traicionados" por la imposición de parámetros organizativos de índole métrica: "la despreocupación o resistencia editora de nuestros poetas o causas como inesperada muerte, nos ofrecen conjuntos poéticos desordenados en los que quizás quepa realizar como editores lo que largamente cuidó el poeta

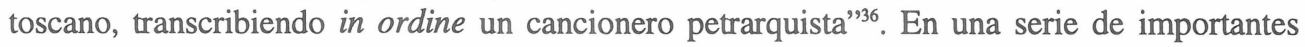
trabajos el profesor Prieto ha marcado las pautas para una reordenación de tal signo, especialmente en el caso de Garcilaso ${ }^{37}$. Una excepción a este panorama general puede ser considerado, por el contrario, el Desengaño de amor en rimas (Madrid, Viuda de Alonso Martín, 1623) de Soto de $\operatorname{Rojas}^{38}$, donde aparece de modo patente el esquema petrarquesco.

\section{Criterios temáticos}

Desde luego no fue el patrón genérico-estrófico el único modelo editorial vigente durante el siglo XVI, pero sí el más innovador y prestigioso, como venimos de comprobar. La herencia cancioneril, compendiada por Hernando del Castillo en 1511, aportaba una seriación de los textos basada en criterios temáticos. La razón no puede ser más obvia: la omnipresencia del octosílabo (interrumpida sólo en ocasiones por el arte mayor) eximía de su polarización con los metros italianizantes, que irrumpen sólo a partir de la edición barcelonesa de 1543. Por tanto, hasta este momento la organización primaria de los cancioneros (colectivos e individuales) se establecerá -aunque con diferencias- en virtud de distinciones argumentales. Así, por ejemplo, las obras de Álvarez Gato en "Poesías amorosas, morales y políticas, religiosas". Pero será el Cancionero General de 1511 (y sus numerosísimas reediciones) el gran modelo dispositivo para toda una serie de compilaciones poéticas quinientistas. Comienza el cancionero agrupando las obras de devoción y moralidad; posteriormente "obras reunidas de diversos autores" (a partir del f. 22), es decir, compartimentadas según los distintos poetas, aunque en su conjunto

\footnotetext{
${ }^{35}$ Madrid, Cátedra, 1984, p. 33

${ }^{36}$ Ibid., p. 36

37 "El «cancionero petrarquista» de Garcilaso", Dicenda. Cuadernos de filología hispánica, 3 (1984), pp. 97-115, reelaborado más tarde en "La poesía de Garcilaso como cancionero", en Homenaje a Manuel Alvar, Madrid, Gredos, 1986, III, pp. 375-385. Fruto de esa línea dispositiva fue su edición del Cancionero (Barcelona, Bruguera, 1982). El mismo esquema argumentativo lo aplica a todos los autores susceptibles de dicha reestructuración en su obra sobre $\mathrm{La}$ poesía española del siglo XVI antes citada. Una propuesta de lectura semejante ha sido admitida por B. López Bueno en su edición de Gutierre de Cetina, Sonetos y madrigales completos, Madrid, Cátedra, 1981; D. Gareth Walters en "Una nueva ordenación de los poemas a Lisi de Quevedo", Criticón, 27 (1984), pp. 55-70, y véase ahora, "Canta sola a Lisi: lector y texto, voz y silencio", Edad de Oro, XIII (1994), pp. 181-188. Cfr. asimismo G. Cabello Porras, "Sobre la configuración del cancionero petrarquista en el Siglo de Oro (la serie de Amarilis en Medrano y la serie de Lisi en Quevedo)", Analecta Malacitana, IV, 1 (1981), pp. 15-34; J. Díez Fernández, "El cancionero a Marfira de don Diego Hurtado de Mendoza", Revista de Filología Española, LXIX (1989), pp. 119-129; T. J. Dadson, "Hacia una posible ordenación de los sonetos a Juana de Lope de Vega" en Crítica textual y anotación filológica en obras del Siglo de Oro, Madrid, Castalia, 1991, pp. 143-157.

${ }^{38}$ A. Prieto, "El «Desengaño de amor en rimas», de Soto de Rojas, como cancionero petrarquista", en Serta Philologica F. Lázaro Carreter, Madrid, Cátedra, 1983, II, pp. 403-412.
} 
son fundamentalmente de tema amoroso; así como la sección de canciones (desde el f. 122); tras un extenso intervalo de "romances con glosas y sin ellas" (f. 131) y diversos géneros cancioneriles (invenciones y letras de justadores, villancicos, preguntas). Finaliza la recopilación a partir del f. 219 con las obras de burlas, sección que desgajada y aumentada más tarde, conformará el Cancionero de obras de burlas provocantes a risa, Valencia, 1519. En este sentido, Montemayor edita sus Obras (Amberes, Juan Steelsio, 1554) "repartidas en dos libros", que se corresponden con las secciones dedicadas a versos profanos y "obras de devoción", respectivamente. Hay que notar, no obstante, que en una subdivisión de este primer nivel se contraponen en ambos casos los metros nacionales a los italianizantes ${ }^{39}$. Con respecto, al Cancionero de nueuo emendado y corregido (Zaragoza, viuda de Bartholomé de Nagera, 1562), que sólo recoge "Obras de humanidad", se establece una distinción entre poemas $\operatorname{amorosos}^{40}$ y "obras de burlas" ${ }^{\text {" }}$. Operan, así pues, en ambas colecciones los dos principios organizadores básicos a lo largo del XVI y el XVII. Lo importante es observar cuál de los dos se adopta como estructura de primer rango. En este sentido, Montemayor se inclina todavía por una distición temática inicial, aunque, claro está, emplea a su vez el criterio estrófico como clasificación suplementaria.

La agrupación de los poemas religiosos al margen de la obra profana se convertirá en canon altamente operativo a lo largo de la centuria y se tipificará definitivamente, en un nutrido grupo de poemarios del XVII, entre los que cabe reseñar, entre otros, los de Jáuregui, Bocángel, Esquilache, Lope, etc ${ }^{42}$. Dos ejemplos del XVI son respectivamente las obras manuscritas de Mosquera de Figueroa ${ }^{43}$ y la Primera parte de las obras (Milán, Pablo Gotardo Poncio [s.a.: c. 1589]) de Francisco de Aldana. En esta última, cuidada por su hermano Cosme, los poemas religiosos abren el volumen separados de "Otros sonetos sobre varios subjectos" y el resto de poesía endecasilábica. Igualmente, Las obras corregidas y emendadas (Madrid, Pierres Cosín, 1573) de Castillejo obedecen a un único sistema clasificatorio basado en distinciones referenciales, ya que se reducen a la práctica exclusiva del octosílabo (a no ser por las composiciones burlescas contra los petrarquistas). Se articula en tres secciones distintas: Libro primero de las obras de amores; Libro segundo de las obras de conversación y pasatiempo y Libro tercero de obras morales y de devoción. Circunstancia totalmente opuesta acontece con el manuscrito Flores de baria poesía (México, 1577) que reúne únicamente poesía en metros italianizantes. En una "Tabla de la diuission de los libros" se explicita el principio organizativo operante: "En el primero se contiene todo lo que se pudo recoger a lo diuino. En el segundo, lo que trata de Amores. En el tercero lo Misiuo. En el quarto lo de burlas. En el quinto cosas indiferentes que no pudieron aplicarse a ninguno de los demas libros". De todos modos sólo se conservan completos el primero y parte del segundo.

\footnotetext{
${ }^{39}$ [Obras profanas]: octosílabos, ff. 1-26; a partir del f. 26, sonetos, canciones, epístolas, églogas; Al f. 75 comienzan Las obras de Deuocion de George de Montemayor: octosílabos (ff. 75-188); endecasílabos (ff. 188-257).

${ }^{40}$ Octosilábicas (ff.1-52v). En el f. 53, Comiençan los Sonetos y Canciones y otras cosas a la medida del verso Italiano...

${ }^{41}$ En el f. 164 comienzan los versos octosilabos y en el f. 172 los endecasílabos.

${ }^{42}$ Cfr. los datos específicos más abajo.

${ }^{43}$ División en "lira sacra" y "lira profana", distinguiendo endecasílabos y octosílabos.
} 
Como venimos de ver, las dos variables que se manejan en la disposición de los corpus poéticos áureos se corresponden con los respectivos principios temático o genérico-estrófico. Cuando funciona uno de ellos como clave organizativa inicial el otro se emplea (puede también no ser utilizado) como secuenciación de segundo nivel. Como ejemplo de la primera posibilidad ya hemos analizado el caso de Montemayor en el XVI y los poemarios que perpetúan los modos cancioneriles. Para insistir en la operatividad de la segunda opción, me remito como ejemplo a los preliminares del manuscrito Chacón donde, en relación a la seriación de las obras gongorinas, adviértese: "Qve aunque la eminencia de las Obras de D. Luis permitía sacarlas de lo común y que en la disposicion de su orden succesiua se atendiese como en los Poëtas Latinos, a la diferencia de los estilos, el temor de que este nueuo modo de colocación no las confunda, i la imitación del Maestro Francisco Sánchez Brocense, i de Hernando de Herrera, que en impressiones de las obras de Garci-Lasso han seguido en esto las de los Poetas Italianos, ha obligado diuidir, i graduar estas Obras según los géneros de sus versos. Si bien en cada vno van subdiuididas las materias, i colocadas en el lugar que parece se deue a cada vna"44. En primer lugar nos las hallamos con la propuesta de un criterio dispositivo novedoso en el panorama editorial del Siglo de Oro, basado en "la diferencia de los estilos" a semejanza de la práctica poética latina. Por esa misma novedad el colector no se resolvió a aplicarlo. No obstante, la propuesta no era del todo original porque don Alonso Carrillo ya había recurrido a ella en 1611 a la hora de organizar secuencialmente las obras de su hermano Luis, tal como lo refiere en una prefación al lector: "Divido sus obras [dice el editor] en estilo y materia. Estilo, como la llaneza de la prosa o dignidad de la poesía: grande, si épica; dulce, si lírica; tierna, si elegíaca; humilde si cómica..." ${ }^{35}$. Frente al modelo latino, de aplicación experimental y anecdótica en la poesía castellana, existe otro, que ya hemos analizado, de raigambre italiana ampliamente ejercitado y fundamentado en distinciones genéricas. Nótese la apelación de Chacón a la clasificación genérico-estrófica, convertida a esas alturas en canon editorial, que, por ejemplo, el Brocense y Herrera habían llevado a cabo con los poemas garcilasianos. Géneros poéticos que quedan compartimentados -según el juicio de Alonso Carrillo- en diferentes materias "colocadas en el lugar que parece se deue a cada vna". Lo cual supone que la subdivisión temática no se presenta de modo aleatorio sino que obedece a un determinado esquema combinatorio, fijado con anterioridad.

Precisamente la resolución de ese escollo dispositivo, la situación de cada una de las series poemáticas en relación con el resto de grupos argumentales, es la que parece depender más directamente que ningún otro aspecto del criterio adoptado por el editor. El análisis de la producción editorial proporciona a este respecto una disparidad de normas divergentes que muestra la libertad (o lo que es igual: la falta de cánones precisos) con que trabajan los colectores. A pesar de lo cual pueden observarse ciertas tendencias comunes que permiten extraer determinadas conclusiones. Colecciones antológicas como el Cancionero General, Flores de baria poesía y el Cancionero de 162846; las ediciones individuales de Aldana y Cristóbal de Mesa (Valle de lágrimas y diversas rimas, Madrid, Juan de la Cuesta, 1607); o los

\footnotetext{
${ }^{44}$ Ed. cit, vol. I.

${ }^{45}$ Luis Carrillo y Sotomayor, Obras, ed. de Rosa Navarro Durán, Madrid, Castalia, 1990, p. 141.

${ }^{46}$ Se inicia con el Heráclito cristiano y segunda harpa a imitación de David de Quevedo (ed. de J. M. Blecua, Madrid, RFE, 1945, pp. 156-180).
} 
manuscritos de Mosquera de Figueroa y el ms. Chacón de Góngora (segunda ordenación) comienzan con el grupo temático de las composiciones religiosas. En muchos de estos poemarios, como contrapartida, las obras humorísticas, eróticas o de contenido satíricoburlesco se emplazan en la posición final (así, en el Cancionero General, Flores de baria poesia, ms. Chacón). También ocurre esto último en los casos de Montemayor (Cancionero), ms. BNM $3888^{47}$, Colodreros, Villamediana (segunda ordenación) o Quevedo ${ }^{48}$. Aunque, a pesar de todo, lo más común suele ser que la ordenación de los conjuntos poéticos se establezca desplazando las obras de moralidad y devoción a la última posición, agrupándose muy frecuentemente en sección aparte de la obras profanas. Ejemplos son Álvarez Gato, en el siglo XV; Montemayor (Obras), Castillejo, Fernández de Heredia ${ }^{49}$, Felipe Mey ${ }^{50}$, Eugenio Salazar ${ }^{51}$, Antonio Ferreira, Silvestre ( $2^{\mathrm{a}}$ ordenación, como se verá a continuación), Lomas Cantoral (segunda ordenación) ${ }^{52}$, Flores de poetas ilustres (1605 y 1611) $)^{53}$, Jáuregui, Bocángel, Paredes, Esquilache, Ulloa.

\footnotetext{
${ }^{47}$ En el ángulo superior derecho del f. 46, donde comienzan las obras de Baltasar del Alcázar, se lee la indicación "este a lo último" (que ilustra sobre la costumbre de cerrar los cancioneros con obras jocosas o de burlas). Cfr. B. López Bueno, "El Cancionero de Fonseca y el manuscrito 3888 de la Biblioteca Nacional de Madrid", en Homenaje a Antonio Gallego Morell, II, Granada, 1989, pp. 243-257, p. 252.

${ }^{48}$ En El Parnaso Español (Madrid, Pedro Coello, 1648), edición a cargo de González de Salas, se establece una división temática de las obras por musas (de las que sólo aparecen las seis primeras, completadas más tarde por Pedro Aldrete en Las tres Musas últimas castellanas, Madrid, Mateo de la Bastida, 1670): Clío, musa I, poesías heroicas; Polimnia, musa II, poesías morales; Melpómene, musa III, poesías fúnebres; Erato, musa IV, sección I, poesías amorosas; sección II, Canta sola a Lisi; Terpsícore, musa V, letrillas satíricas y burlescas; Talía, musa VI, poesías jocoserias, que llamó burlescas el autor.
}

${ }^{49}$ Las obras, assi temporales como espirituales, Valencia [Joan Mey], 1562: -Algunas obras de burlas...-Obras de deuoción (aquí se incluyen sonetos y una elegía. Estas composiciones italianizantes cierran el volumen).

${ }^{50}$ Del Metamorfoseos de Ovidio en octava rima, traducido por Felipe Mey en siete libros. Con otras cosas del mismo, Tarragona, 1586. Las Rimas ocupan 62 pp. con su dedicatoria. Están compuestas por sonetos, epístolas amorosas, octavas (La fuente de Alcover, pp. 25-47). En la p. 48 comienzan las poesías a lo divino, en metro italianizante.

${ }^{51}$ Silva de Poesía, ms. inédito de la Academia de la Historia (C-56), preparado por el autor para la imprenta. Su ordenación, por tanto, responde plenamente a la voluntad autorial, privilegiando la alternancia de formas métricas (como Boscán o Lomas Cantoral), acorde con el "vario stile", una de las constantes renacentistas, siguiendo el ejemplo de Petrarca. Salazar en dos hojas manuscritas preliminares ofrece a sus hijos una especie de testamento literario donde consigna detalladamente los más mínimos aspectos de la pretendida edición. Señala así pues que las obras aparecen "continuadas por el orden que deben estar". Se divide el conjunto en cuatro partes, la última de las cuales contiene cartas en prosa. Las tres primeras engloban:

-Primera parte de la Silva, en que están las obras que Eugenio de Salazar hizo a contemplación de Doña Catalina Carrillo, su amada mujer. Se subdivide en dos partes, y en la primera están las Obras pastoriles (églogas).

-Segunda parte de la Silva de Poesía, donde hay obras que el autor compuso a contemplación de diversas personas y para diversos fines.

-Tercera parte de la Silva de Poesía que, contiene las obras de devoción del autor, dividida en tres partes: primera en que están las obras pastoriles; segunda en que se contienen las obras en metro castellano (=de arte real); tercera en que hay sonetos y líricos y salmos y otras cosas. J. M. Blecua Perdices, La obra poética del ms. C-56 de la Biblioteca de la Real Academia de la Historia, Barcelona, 1970 (tesis doctoral). Apud Prieto, op. cit., vol. II, pp. 655 y ss.

${ }^{52}$ Como señala J. I. Díez Fernández, art. cit., p. 79, "Como un refuerzo de especial intensidad, Lomas Cantoral ha ordenado con cuidado los finales de los tres libros siguiendo una estructura paralelística en la disposición de los poemas y una intensidad creciente en los contenidos morales y religiosos... Cada uno de ellos termina con dos textos de contenido moralizante o religioso".

${ }^{53}$ Primera parte de las Flores de poetas ilustres de España. Dividida en dos libros. Ordenada por Pedro Espinosa, Valladolid, Luis Sánchez (1605) y Segunda parte de las flores de poetas ilustres de España. Ordenadas por Juan Antonio Calderón (1611). Dentro de la polaridad general entre lo profano (libro I) y lo religioso (libro II) existe una 
No puedo proponer una explicación totalmente convincente para descubrir los resortes funcionales que subyacen a ambas estrategias dispositivas. Pero sí resulta evidente que los poemas de índole religiosa suelen ocupar un lugar destacado del resto de las composiciones, bien iniciando el volumen poético, como pórtico más noble y elevado de la colección, bien cerrándolo en tanto colofón espiritual. La primera opción, con todo, parece más abundante en las compilaciones antológicas (Cancionero General, Flores de baria poesia, aunque también el ms. Chacón en su segunda ordenación) que, estableciendo un arco de marcada tensión argumental, cancelan su andadura poética con las "obras de burlas". Una nuevo condicionante, de tipo métrico esta vez, quizás lo constituya la naturaleza primordialmente octosilábica de los textos reunidos. Fijémonos por un momento en la edición de Gregorio Silvestre, cuyos tres primeros libros recopilan las coplas castellanas. Según las palabras de Cáceres en el primero de todos se pusieron: "[...] aquellas [composiciones] de que los antiguos poetas españoles usaron. Lamentaciones, coplas, glosas, canciones villanescas y villancicos, entre las quales tuuimos cuydado de poner las más graues primero, las pastorales después, y últimamente las de donayre, porque según su calidad lleuen el lugar que merescen [...]"\$4 . Gradación, dentro del seno de la poesía de tradición española -no lo olvidemos- fundamentada en un descenso conceptual desde la materia más grave a la más intrascendente. Pero, sigamos con el prólogo al cuarto libro de las obras de Silvestre, donde se hace balance de la estructuración de los precedentes. Si el primero recogía la producción profana (es decir no religiosa, aunque como acabamos de comprobar con matizaciones cualitativas), no obstante como anuncia el editor, "en el segundo se pusieron las fábulas, Audiencia y Residencia, por ser también obras profanas, aunque de excelente grauedad y autoridad. En el tercero las obras morales y de deuoción que (como está visto) son de ingenio subtil y singular artificio"s5. En definitiva, la producción en octosílabos iría conformada por un libro inicial de poesía profana, previamente articulado; uno

separación por series temáticas, géneros, metros y tonos estilísticos. Agrupación que se rompe por momentos buscando una complicación estructural manierista que se decanta por el pluritematismo y la fragmentación y los efectos de variedad y contraste (según se explicita en el prólogo al lector: "Creedme, Señor, que si no temiera enfadaros, no hubiera buscado tan varia breuedad, pues esta trae la hermosura y el gusto"), como ha estudiado J. Lara Garrido, "Notas en torno a las Flores de poetas ilustres de Pedro de Espinosa", Analecta Malacitana, II, 1 (1979), pp. 175-182 y sobre lo que ha insistido A. Gil Ribes, "El ornatus y la dispositio en la edición de textos poéticos del Siglo de Oro (el Libro de Retratos de F. Pacheco y las Flores de 1605 y 1611)", en La edición de textos, ed. de P. Jauralde et al., Londres, Támesis, 1990, pp. 219-226. Todo ello supone la ruptura con los Romanceros donde falta la variedad de formas. Este principio influyó en la organización de libros como la Segunda parte del Romancero General de Miguel de Madrigal polarizada en torno a criterios métricos: lírica tradicional/lírica italianizante.

${ }^{54}$ Prólogo al libro IV, ff. 296-296v.

${ }_{55}$ Copio más por extenso el prólogo citado. "Donde ay tanta variedad de obras, y tales como Gregorio Silvestre compuso, mal se pudieran todas poner en dos, ni tres libros. Y así por euitar confusión nos paresció diuidirlas en quatro, pues la diuissión es causa de claridad. En el primero pusimos aquellas de que los antiguos poetas españoles usaron. Lamentaciones, coplas, glosas, canciones villanescas y villancicos, entre las quales tuuimos cuydado de poner las más graues primero, las pastorales después, y últimamente las de donayre, porque según su calidad lleuen el lugar que merescen [...] En el segundo se pusieron las fábulas, audiencias y residencia, por ser también obras profanas, aunque de excelente grauedad y autoridad. En el tercero las obras morales y de deuoción que (como está visto) son de ingenio subtil y singular artificio. Aora en el quarto y último ponemos los sonetos y canciones y epístolas que hizo y la fábula de Narciso. Van también algunos sonetos de amigos suyos embiados a él, pues todo es concerniente a las obras del mismo autor. No nos pareció diuidir los sonetos amorosos de los morales, por ser pocos todos y de la misma compostura y porque tampoco están diuididos en los poetas toscanos, a quien imita como el Sannazaro y el Petrarca y los demás" (ff. 296-296v.). Véase la preocupación organizativa de Cáceres, que se plantea incluso el método de división temática de los sonetos, guiándose de los modelos italianos. 
segundo de poesía también profana, pero de "excelente gravedad y autoridad", gravedad que llega a sus más altas cotas con las poesías religiosas recogidas en el tercero. Por tanto, -y es precisamente el punto de contradicción- se establecen dos criterios contrapuestos, uno más amplio, o de primer nivel, que apuesta por la progresión de lo profano a lo moral y religioso; otro, pertinente sólo en el ámbito del primer libro, que se decide por la degradación hacia lo satírico-burlesco. Incluso dentro, así pues, de un mismo poemario pueden funcionar las dos tendencias opuestas, si bien en el caso concreto que nos ocupa parece triunfar la primera opción, que se aplica también a los poemas del libro cuarto: $1^{\circ}$, cancionero amoroso; $2^{\circ}$, poemas circunstanciales y amistosos; $3^{\circ}$, Fábula de Narciso; $4^{\circ}$, sonetos morales y religiosos. Propondré únicamente un ejemplo más, esta vez de la mano de Antonio Ferreira, cuyos Poemas lusitanos (Lisboa, Pedro Craesbeeck, 1598), colección de 102 sonetos, se ordenan siguiendo el esquema contemporáneo, muy parecido al que Faria e Sousa, sin ir más lejos, aplicó a los sonetos de Camoens (y anteriormente en la Fvente de Aganipe, Madrid, Carlos Sánchez Bravo, 1646), divididos "por materias, como se usa oy, y como es razón que sea, poniendo primero los amorosos, después los heroicos, luego los morales, y sacros"

El principio rector de una gradación de este tipo podría entenderse como la aplicación del modus per incrementum ${ }^{57}$ o en terminología retórica más actual de la "ley de los miembros crecientes" ${ }^{\prime \prime 8}$, que consiste en la ordenación de las partes de un todo reservando para la posición final el miembro más fuerte o, en este caso concreto, de mayor intensidad referencial. Los tratadistas (entre ellos Quintiliano) consideran este tipo de distribución progresiva como la manifestación más evidente del ordo naturalis, es decir, "el orden que nos da la naturaleza o que consideramos normalmente como dado por la naturaleza" 59 . Cualquier desviación que contravenga la seriacióm natural consistirá, por tanto, en la asunción de un ordo artificialis. Ahí puede radicar el motivo de la poderosa tendencia de estructurar los cancioneros mediante una dispositio ascendente desde el punto de vista semántico. Por lo mismo que la interrupción de ese orden natural (semejante a los principios de la naturaleza), y su sustitución por otro decreciente supone la inobservancia de la norma general. Otro fundamento retórico referente a la dispositio que me parece importante poner de relieve es el que atañe a la organización bipartita de los contenidos (entiéndase "lo profano" frente a "lo religioso") basada en el recurso de la antítesis argumental e impuesta por un deseo de destacar la "energía" del conjunto" 60 . Frente a ello la estructura trimembre de los grupos genéricos respondería a la decisión de dotar de integridad a la totalidad, subrayando la perfecta articulación de las tradiciones poéticas nacionales e italianizantes, manifestaciones alternas y perfectamente aismiladas, con mutuas y fructíficas interferencias (según la interpretación que de ellas se hace a partir de 1580). Por

\footnotetext{
${ }^{56}$ Los Poemas lusitanos se dividen en dos libros: el primero con 58 sonetos (todos amorosos, dedicados a su primera esposa María Pimentel); el segundo con 44: los trece primeros "in morte" de doña María; del 14 al 34, poemas ocasionales dedicados a amigos y patrones; los diez últimos de asuntos religiosos. Cfr. T.F. Earle, "A Portuguese Sonnet Sequence of the Sixteenth Century", Bulletin of Hispanic Studies, LXIII (1986), pp. 225-234. La cita ha sido tomada de la p. 226.

${ }^{57}$ C. Chirii Fortunatiani, Artis rethoricae libri III, in C Halm, Rhetores Latini minores, Lipsiae, 1863. 3, 1. Apud H. Lausberg, Manual de retórica literaria, Madrid, Gredos, 1990, I, p. 374.

${ }^{58}$ W. Havers, Handbuch der erklärenden Syntax, Heidelberg, 1931, p. 178. Apud Lausberg, ibid.

${ }^{59}$ H. Lausberg, Manual de retórica literaria, I, p. 373.

${ }^{60}$ H. Lausberg, op. cit., p. 368.
} 
todo lo cual, y muy al contrario, la escisión bimenbre de los géneros, común, como se ha analizado anteriormente, a gran parte de los poemarios del Quinientos pretende evidenciar los antagonismos cualitativos: la diferencia cronológica de composición entre ambas posibilidades, tal como se conceptualiza en ese momento (por ejemplo, en el caso de Silvestre). Tal vez pueda esgrimirse este argumento a la hora de explicar las transformaciones dispositivas sufridas en el paso del siglo XVI al XVII ${ }^{61}$.

\footnotetext{
${ }^{61}$ No me he ocupado en el presente trabajo de analizar las consecuencias ecdóticas que pueden desprenderse de la organización de los libros poéticos en el Siglo de Oro, a la hora de abordar su eventual edición crítica: es decir, la problemática que origina la disposición textual de un conjunto poético, las más de las veces desorganizado, pero que ha de ofrecerse al lector cohesionado en virtud de algún criterio estructurante. Estudié la aplicación concreta de tales tendencias y patrones al editar las obras de Baltasar del Alcázar (cfr. mi Tesis Doctoral inédita, La poesía de Baltasar del Alcázar: análisis textual y edición crítica, Sevilla, 1996). De un modo general y reparando en algunos de los casos que yo mismo he aducido, lo ha tratado magistralmente Begoña López Bueno en su trabajo en prensa, "Algunos problemas cruciales en la edición de textos poéticos. La ordenación del corpus", que presentó como conferencia en el ciclo "La Poesía de los Siglos de Oro", Sesión I, "La tradición textual" (29-XI-1993) organizado por la Casa de Velázquez.
} 